\title{
Extinction circuits for fear and addiction overlap in prefrontal cortex
}

\author{
Jamie Peters, ${ }^{1,3}$ Peter W. Kalivas, ${ }^{2}$ and Gregory J. Quirk ${ }^{1}$ \\ ${ }^{1}$ Departments of Psychiatry, Anatomy, and Neurobiology, University of Puerto Rico School of Medicine, San Juan, Puerto Rico \\ 00936; ${ }^{2}$ Department of Neurosciences, Medical University of South Carolina, Charleston, South Carolina 29425, USA
}

\begin{abstract}
Extinction is a form of inhibitory learning that suppresses a previously conditioned response. Both fear and drug seeking are conditioned responses that can lead to maladaptive behavior when expressed inappropriately, manifesting as anxiety disorders and addiction, respectively. Recent evidence indicates that the medial prefrontal cortex ( $\mathrm{mPFC}$ ) is critical for the extinction of both fear and drug-seeking behaviors. Moreover, a dorsal-ventral distinction is apparent within the $\mathrm{mPFC}$, such that the prelimbic (PL-mPFC) cortex drives the expression of fear and drug seeking, whereas the infralimbic (IL-mPFC) cortex suppresses these behaviors after extinction. For conditioned fear, the dorsal-ventral dichotomy is accomplished via divergent projections to different subregions of the amygdala, whereas for drug seeking, it is accomplished via divergent projections to the subregions of the nucleus accumbens. Given that the mPFC represents a common node in the extinction circuit for these behaviors, treatments that target this region may help alleviate symptoms of both anxiety and addictive disorders by enhancing extinction memory.
\end{abstract}

Emotional memories, both in the aversive and appetitive domains, are important for guiding behavior. Regulating the expression of these memories is critical for mental health. Extinction of classical conditioning is one form of emotion regulation that is easily modeled in animals. In the aversive domain, a conditioned stimulus (CS) is typically paired with a shock, while in the appetitive domain, a CS is paired with the availability of food or drug reward. Repeated presentation of the CS in the absence of the reinforcer leads to extinction of conditioned fear or drug-seeking behaviors. In recent years, there have been great advances in our understanding of the neural circuitry responsible for this form of inhibitory learning (for reviews, see Cammarota et al. 2005; Maren 2005; Myers and Davis 2007; Quirk and Mueller 2008). The prefrontal cortex has been strongly implicated in fear expression (Powell et al. 2001; Vidal-Gonzalez et al. 2006; Corcoran and Quirk 2007) and fear extinction (Herry and Garcia 2002; Milad and Quirk 2002; Gonzalez-Lima and Bruchey 2004; Hugues et al. 2004; Burgos-Robles et al. 2007; Hikind and Maroun 2008; Lin et al. 2008; Mueller et al. 2008; Sotres-Bayon et al. 2008), and more recently, in expression of drug seeking after extinction (Peters et al. 2008a,b). These findings are consistent with a welldocumented role of the prefrontal cortex in executive function and emotional regulation (Miller 2000; Fuster 2002; Quirk and Beer 2006; Sotres-Bayon et al. 2006).

In this review, we propose that the medial prefrontal cortex (mPFC) regulates the expression of both fear and drug memories after extinction, through divergent projections to the amygdala and nucleus accumbens, respectively. Extinction failure in the aversive domain can lead to anxiety disorders (Delgado et al. 2006; Milad et al. 2006), while extinction failure in the appetitive domain can lead to relapse in addicted subjects (Kalivas et al. 2005; Garavan and Hester 2007). A common neural circuit for extinction of fear and drug memories would suggest shared mechanisms and treatment strategies across both domains.

\footnotetext{
${ }^{3}$ Corresponding author.
}

E-mail petersjl.upr@gmail.com; fax (787) 999-3057.

Article is online at http://www.learnmem.org/cgi/doi/10.1101//m.1041309.
Prefrontal control of extinction of conditioned fear

The earliest evidence that the prefrontal cortex might be a critical locus for the extinction of conditioned fear was the observation that prefrontal lesions led to a selective deficit in extinction (Morgan et al. 1993; Sotres-Bayon et al. 2006). Specifically, the ventral subdivision of rodent medial prefrontal cortex, termed infralimbic cortex (IL-mPFC), was responsible for this effect (Morgan and LeDoux 1995; Fig. 1). Since then, accumulating evidence has suggested that plasticity in IL-mPFC is important for extinction memory. Protein synthesis inhibitors (Santini et al. 2004), MAPK inhibitors (Hugues et al. 2004), NMDA receptor blockers (Burgos-Robles et al. 2007; Sotres-Bayon et al. 2008) or pharmacological inactivators (Sierra-Mercado et al. 2006) injected locally into IL-mPFC disrupt the ability to subsequently recall extinction. These data support the long-held notion that extinction learning creates an inhibitory memory trace distinct from that created by conditioning (Konorski 1967; Rescorla 2004).

Activity in IL-mPFC is a key mediator of the inhibitory memory underlying extinction. Single-unit recordings reveal that CS responsiveness in IL-mPFC neurons develops only after extinction learning has occurred, and correlates with the degree of extinction recall (Milad and Quirk 2002). Plasticity within the IL$\mathrm{mPFC}$ has also been demonstrated to promote the maintenance of extinction memory, resulting in the suppression of conditioned fear (Herry and Garcia 2002). Finally, agents that enhance metabolic activity in IL-mPFC (Gonzalez-Lima and Bruchey 2004) and direct electrical stimulation of IL-mPFC (Milad et al. 2004; VidalGonzalez et al. 2006; Fig. 2B), both promote extinction expression. Collectively, these data suggest that IL-mPFC mediates fear inhibition.

Recent evidence indicates that the more dorsally located prelimbic prefrontal cortex (PL-mPFC) increases fear expression (Fig. 1). Whereas IL-mPFC neurons increase activity to the CS when fear is low, PL-mPFC neurons increase firing during early extinction, when fear is high (Baeg et al. 2001; Gilmartin and McEchron 2005; Laviolette et al. 2005; Burgos-Robles et al. 2009). Furthermore, the time course of CS-evoked conditioned responses in PL-mPFC neurons is highly correlated with the time course of 


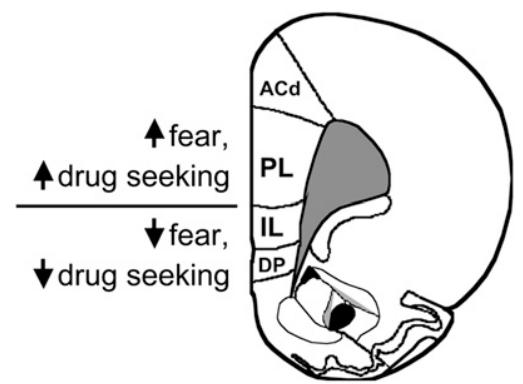

Figure 1. Dorsal versus ventral regions of rodent medial prefrontal cortex differentially control fear and drug seeking. The four major subdivisions of rodent medial prefrontal cortex are depicted along the Paxinos and Watson anatomical boundaries ( $3.0 \mathrm{~mm}$ anterior to bregma) (Paxinos and Watson 2005). Activity in the prelimbic (PL) region promotes the expression of conditioned fear and cocaine-seeking behavior. Dorsal to PL is the dorsal anterior cingulate cortex (ACd), which may also promote fear and drug seeking. The infralimbic (IL) cortex, which lies ventral to $\mathrm{PL}$, promotes the extinction of conditioned fear and cocaineseeking behavior. The ventral-most dorsopeduncular cortex (DP) may resemble IL in the ability to inhibit fear and drug seeking. Hence, dorsal regions of medial prefrontal cortex increase fear and drug seeking (arrows up), while ventral regions exert the opposite effect on behavior, decreasing both fear and drug seeking (arrows down).

conditioned freezing (Burgos-Robles et al. 2009). Microstimulation of PL-mPFC increases conditioned fear (Vidal-Gonzalez et al. 2006; Fig. 2A), and pharmacological inactivation of PL-mPFC reduces conditioned fear (Blum et al. 2006; Corcoran and Quirk 2007). Stimulation of more dorsal regions, such as dorsal anterior cingulate cortex (ACd-mPFC), produced no discernible effects on fear (Vidal-Gonzalez et al. 2006); however, a recent study found that ACd-mPFC inactivation was capable of reducing fear expression, and ACd-mPFC neurons are activated by fear stimuli (Bissiere et al. 2008). This suggests that ACd-mPFC may resemble PL-mPFC as a fear-activating site. Thus, there is a functional dorsal-ventral divide within the mPFC which can be conceptualized as an "onoff" switch regulating fear expression (Fig. 1).

\section{Prefrontal outputs that modulate fear expression}

Distinct subdivisions of mPFC could differentially regulate fear expression through divergent targets within the amygdala. The projections from $\mathrm{mPFC}$ to the amygdala are glutamatergic, excitatory projections (Brinley-Reed et al. 1995). The PL-mPFC region projects primarily to the basal amygdala (BA) (Vertes 2004; Gabbott et al. 2005), which is critical for the expression of conditioned fear (Anglada-Figueroa and Quirk 2005; Herry et al. 2008). The main sites of fear memory storage in the amygdala are the lateral amygdala (LA) (Quirk et al. 1995; Repa et al. 2001), as well as the central nucleus (CE) of the amygdala (Wilensky et al. 2006; Zimmerman et al. 2007). Because there is no direct projection from LA to CE output neurons, the LA is thought to drive fear by an intermediate local projection to the BA, which in turn excites the CE (Blair et al. 2001). PL-mPFC thus excites the CE, in the same manner as the LA, by a relay synapse in the BA (Likhtik et al. 2005). Thus, the net result of increased activity in PL-mPFC is an increased output from CE (Fig. 3), which generates fear via projections to the hypothalamus and brainstem (Hopkins and Holstege 1978; LeDoux et al. 1988).

The IL-mPFC also sends an excitatory projection to the amygdala, but preferentially targets areas containing GABAergic neurons in the lateral subdivision of central nucleus and in the intercalated cell masses (ITCs), which are positioned between the basolateral amygdala complex (BLA) and the CE (McDonald et al. 1996; Berretta et al. 2005; Fig. 3). These ITCs may be a site of plasticity for extinction memory, as they show NMDA receptordependent plasticity (Royer and Pare 2002). Activity in IL-mPFC may then promote extinction by engaging ITC-mediated feedforward inhibition of the CE.

Consistent with this model of amygdala control of fear expression, recent evidence indicates that extinction may involve a combination of enhanced excitatory drive to ITCs and diminished excitatory output from LA. Specifically, Jüngling et al. (2008) found evidence supporting a presynaptic enhancement of glutamatergic transmission onto ITCs during extinction of conditioned fear. Involvement of ITCs in expression of extinction memory was

A.
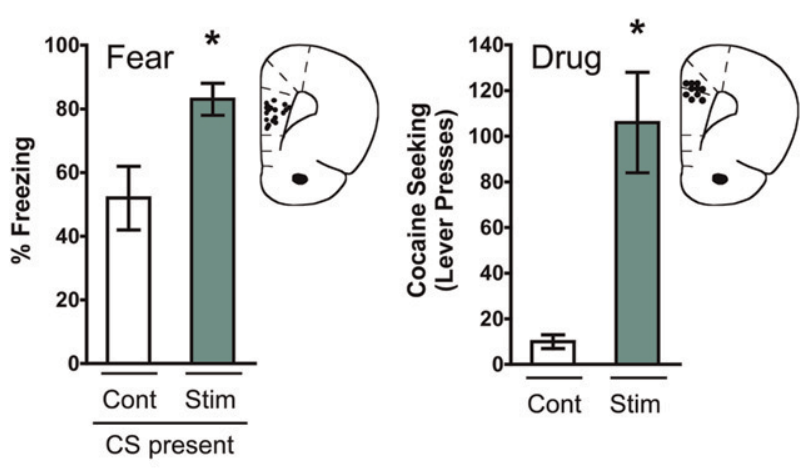

B.
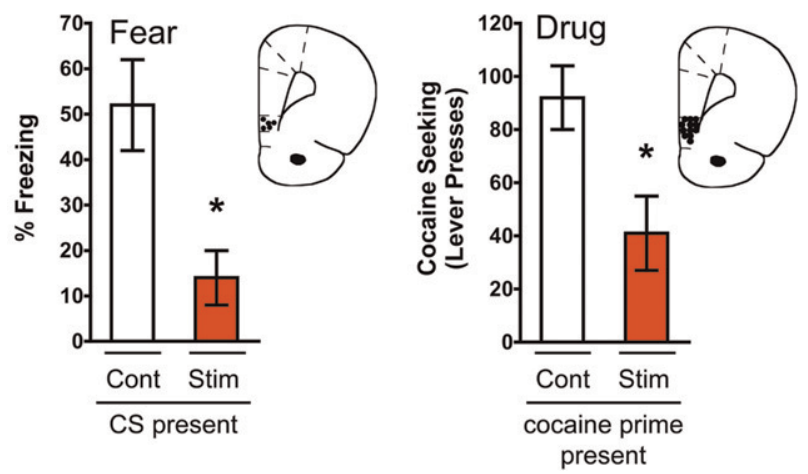

Figure 2. Enhancing activity in prelimbic cortex increases fear and drug seeking, while enhancing activity in infralimbic cortex has the opposite effects. ( $A$ ) Electrical microstimulation (stim) of prelimbic (PL) cortex enhances conditioned fear relative to unstimulated controls (cont). Values on the $y$-axis represent percent freezing to the shock-paired tone CS. Microstimulation was conducted on the first extinction session (VidalGonzalez et al. 2006). For drug seeking, PL was activated by local infusion of dopamine ( $30 \mathrm{nmol} / \mathrm{side}$ ) before an extinction session, after extensive extinction training. Baseline extinction responding on the session prior to the PL test is shown as a control (cont). Values on the $y$-axis represent presses on the previously cocaine-paired lever (McFarland and Kalivas 2001). (B) Electrical microstimulation (stim) of infralimbic (IL) cortex reduces conditioned fear relative to unstimulated controls (cont). Data collected from the same study (Vidal-Gonzalez et al. 2006) on PL stimulation shown in $A$. For drug seeking, IL was activated by local infusion of AMPA ( $0.1 \mathrm{nmol} /$ side) before a cocaine-primed $(10 \mathrm{mg} / \mathrm{kg}$, i.p.) reinstatement test, after extensive extinction training. Reinstatement of pressing on the previously cocaine-paired lever is used as a measure of cocaine seeking ( $y$-axis). Reinstatement values for animals microinfused with vehicle prior to the relapse test are shown as controls (cont) (Peters et al. 2008a). Representative placements of the microstimulating electrode or infusion needle-tips in PL $(A)$ and IL $(B)$ are shown for both fear and drug-seeking experiments to the right of each graph. $\left(^{*}\right) P<0.05$ compared with respective control condition. 


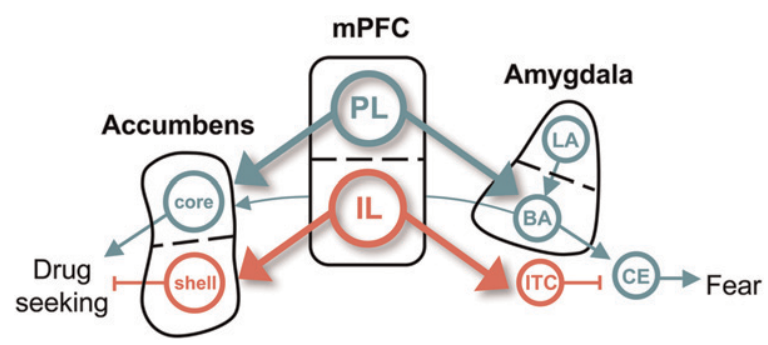

Figure 3. Circuit diagram depicting prefrontal regulation of conditioned fear and cocaine-seeking behaviors. The dorsal and ventral subdivisions of medial prefrontal cortex (PFC) are shown at the center, with their respective outputs to the amygdala controlling fear shown at right, and those to the nucleus accumbens controlling cocaine seeking shown at left. The prelimbic (PL) cortex projects to the basal (BA) nucleus of the amygdala, which excites the central (CE) nucleus of the amygdala, thereby promoting the expression of conditioned fear. The BA also receives excitatory input from lateral (LA) amygdala, which also drives the expression of conditioned fear. The infralimbic (IL) cortex, in contrast, excites a class of GABAergic inhibitory neurons known as the intercalated (ITC) cell masses. These neurons inhibit the $C E$, thereby inhibiting conditioned fear and promoting extinction. By comparison, $\mathrm{PL}$ and IL control cocaine seeking via their differential projections to the core and shell subdivisions of the nucleus accumbens. The PL projects to the core, which promotes the expression of cocaine-seeking behavior. For cueinduced cocaine seeking, this may involve an intermediate projection through the BA to access the core (thin green line). The IL projects to the shell, which promotes the expression of extinction. It remains to be determined how output from these two divisions of the accumbens differentially affects cocaine-seeking behavior (see text for details). Green depicts pathways that activate fear and cocaine seeking. Red depicts pathways that inhibit fear and cocaine seeking.

directly tested by Pare and coworkers, who showed that selective lesions of ITCs caused extinguished fear to return (Likhtik et al. 2008). In addition to potentiation of inhibition, recent evidence suggests that extinction involves depotentiation of excitiatory pathways (Kim et al. 2007). These authors found that extinction reversed the conditioning-induced increases in AMPA receptor surface expression in the LA, and blocking AMPA receptor endocytosis within the LA impaired extinction. Collectively, these data suggest that extinction results from a combination of enhanced drive to amygdala regions that inhibit fear expression (ITCs) and diminished output from regions that drive fear expression (LA), an idea supported by recent computational modeling (Li et al. 2009).

\section{Prefrontal control of extinction of conditioned drug seeking}

For drug-seeking behavior, we focus on a cocaine self-administration model of relapse. In this model, rats learn to press a lever for intravenous cocaine delivery in a cocaine-specific context over several days until responding is stable. When cocaine is replaced with saline, extinction of responding on the cocaine-paired lever occurs over a period of 1-2 wk. Following extinction, cocaine seeking can be reinstated by presenting a discrete cue that was paired with cocaine delivery, low doses of cocaine itself, or stress (De Wit and Stewart 1981; Shaham et al. 2003; Epstein et al. 2006). This reinstatement of drug seeking following extinction is thought to model clinical relapse. Relapse-inducing stimuli can activate cocaine seeking via dopaminergic mechanisms within the PL-mPFC (Ciccocioppo et al. 2001; McFarland and Kalivas 2001; McFarland et al. 2004; Fig. 2A). Both D1 and D2 dopamine receptors have been implicated in the ability of prefrontal dopamine to trigger relapse, though the evidence is somewhat stronger for D1 receptors (Ciccocioppo et al. 2001; Capriles et al. 2003; Sanchez et al. 2003; Sun and Rebec 2005). Indeed, administering cocaine directly into the PL-mPFC triggers cocaine relapse (Park et al. 2002), presumably due to local inhibition of the dopamine transporter (Komiskey et al. 1977).

The neural circuits mediating relapse to cocaine seeking have been recently mapped by pharmacologically inactivating discrete brain regions prior to the reinstatement test (McFarland and Kalivas 2001; McFarland et al. 2004; See 2005). The PL-mPFC was found to be critical for cocaine relapse, triggered by multiple forms of relapse-inducing stimuli, including cocaine-paired cues, cocaine itself, and stress (McFarland and Kalivas 2001; Capriles et al. 2003; McLaughlin and See 2003; McFarland et al. 2004; Di Pietro et al. 2006; but see Di Ciano et al. 2007). Thus, infusion of pharmacological inactivators or dopamine antagonists into PLmPFC leads to decreased pressing for cocaine during relapse testing. More recently, inactivation of PL-mPFC was also found to reduce relapse for heroin induced by both heroin-paired cues and heroin itself (LaLumiere and Kalivas 2008; Rogers et al. 2008; but see Schmidt et al. 2005). The majority of these studies suggest that the PL-mPFC represents a final common node in the relapse circuit for both cocaine and heroin. Hence, similar to PL-mPFC's role in fear expression, PL-mPFC also supports theexpression of conditioned drug-seeking behavior (Fig. 1).

Given its proposed inhibitory role, inactivation of IL-mPFC should result in increased pressing for cocaine after extinction. This, however, has not been observed in previous studies (McFarland and Kalivas 2001; Capriles et al. 2003; Fuchs et al. 2005; McLaughlin and Floresco 2007; Koya et al. 2008). Two factors can account for this. The first is that IL-mPFC was typically inactivated prior to administering some relapse-inducing stimulus, which results in high levels of cocaine seeking, against which further increases in cocaine seeking would be difficult to detect (i.e., a ceiling effect). The second is that discrete cues paired with cocaine delivery were never extinguished prior to the IL-mPFC test; thus, Pavlovian extinction was incomplete (Capriles et al. 2003; Koya et al. 2008). If IL-mPFC is inactivated following extinction of cocaine or heroin seeking, there is a robust return of drug seeking, consistent with an inhibitory role for this structure (Ovari and Leri 2008; Peters et al. 2008a,b). Furthermore, pharmacologically stimulating IL-mPFC prior to a relapse test reduces the degree of observed relapse (Peters et al. 2008a; Fig. 2B), further implicating the IL-mPFC in suppression of drug seeking. Collectively, the available evidence suggests that PL-IL supply an on-off switch for expression of conditioned drugseeking behavior, as they do for expression of conditioned fear, especially after extinction (Figs. 1, 2).

\section{Prefrontal outputs that modulate drug seeking}

Just as distinct prefrontal-amygdala connections support an onoff switch for conditioned fear, the anatomy of prefrontal-accumbens connections support an on-off switch for cocaine seeking. The nucleus accumbens core (core) receives input primarily from the PL-mPFC, whereas the nucleus accumbens shell (shell) receives input primarily from the IL-mPFC (Sesack et al. 1989; Brog et al. 1993; Voorn et al. 2004). Glutamate released from PL$\mathrm{mPFC}$ within the core triggers relapse for both cocaine and heroin (McFarland et al. 2003, 2004; LaLumiere and Kalivas 2008; Fig. 3) via AMPA-mediated transmission (Cornish and Kalivas 2000; Park et al. 2002; LaLumiere and Kalivas 2008). The IL-mPFC projection to the shell, in contrast, promotes extinction of cocaine seeking, as disconnection of this pathway after extinction results in a return of conditioned cocaine seeking reminiscent of that seen with ILmPFC inactivation (Peters et al. 2008a). Furthermore, as extinction proceeds, shell expression of the GluR1 subunit of the AMPA receptor increases, but core expression does not (Sutton et al. 2003). Shell expression of GluR1 correlates positively with the 
degree of behavioral extinction and negatively with cue-induced relapse (Sutton et al. 2003). Thus, the IL-mPFC is a candidate glutamatergic input to the shell that may be responsible for signaling extinction (Fig. 3).

Both the core and the shell send GABAergic projections to the ventral pallidum, which controls motor output necessary for drug seeking (Walaas and Fonnum 1979; Zahm and Heimer 1990; Heimer et al. 1991; Kalivas et al. 1999). GABA agonists injected into the ventral pallidum reduce cocaine seeking (McFarland and Kalivas 2001), and in some cases locomotion (Mogenson and Nielsen 1983; Hooks and Kalivas 1995). Hence, the GABAergic projection from the accumbens to the pallidum would be expected to suppress drug seeking. This is consistent with IL-mPFC-mediated inhibition of drug seeking after extinction, but is not consistent with PL-mPFC-mediated activation of drug seeking. Activation of drug seeking via the core may involve the neuropeptide enkephalin. Medium spiny neurons projecting from the core to the pallidum express enkephalin (Zahm et al. 1985), which, when released during high frequency firing, could stimulate pallidal $\mu$ opiod receptors (Waldhoer et al. 2004) causing a reduction in local GABA levels and reduced inhibition within the pallidum (Kalivas et al. 2001; Schroeder and Schneider 2002). Indeed, a $\mu$ opiod-dependent decrease in pallidal GABA is necessary for cocaine relapse (Tang et al. 2005), an effect likely mediated through co-release of enkephalin in the accumbens core-pallidal pathway (Torregrossa et al. 2008). Thus, PL-mPFC projections through core to the pallidum could conceivably activate drug seeking.

\section{Caveats to the model}

Though our model proposes an overlap in the extinction circuits for fear and addiction within the prefrontal cortex and a divergence in the subsequent downstream effectors responsible for the expression of each of these behaviors, this divergence may not be as distinct as we propose. In addition to the expression of conditioned fear, the amygdala may also play a role in the expression of conditioned drug seeking. Activity in the BA is a necessary component of the circuitry underlying cue-induced drug seeking (Kantak et al. 2002; McLaughlin and See 2003). This is presumably mediated in part by reciprocal connections between the PL-mPFC and BA, as well as projections from the BA directly to the core (Di Ciano and Everitt 2004; Fuchs et al. 2007). Thus, at least for cue-induced drug seeking, there appears to be an overlap in the role of the projection from PL-mPFC to BA in initiating both fear and drug seeking (Fig. 3). Importantly, the CE of the amygdala is also capable of initiating drug seeking, particularly for stress-induced reinstatement (Erb et al. 2001; Leri et al. 2002; McFarland et al. 2004). Hence, enhanced CE output may be a common mechanism underlying the initiation of both fear and drug-seeking behavior.

In addition to its role in the expression of drug-seeking behavior, the nucleus accumbens may also be involved in the expression of fear. For instance, pharmacological inactivation of the shell is sufficient to elicit place avoidance as well as defensive fear behaviors in rats (Reynolds and Berridge 2001, 2002). While this suggests that activity in the shell may tonically inhibit fear expression, there is also some evidence to the contrary, where shell lesions have reduced fear expression (Jongen-Relo et al. 2003). However, the literature is mixed, perhaps partially owing to the general disregard for core vs. shell distinctions (Haralambous and Westbrook 1999; Schwienbacher et al. 2004; for review, see Levita et al. 2002). Future studies are necessary to determine the extent to which the amygdala and accumbens are exclusively dedicated to the expression of fear and drug seeking, respectively.

\section{A common prefrontal pathology for PTSD and addiction?}

There is increasing evidence supporting the notion that posttraumatic stress disorder (PTSD) is associated with extinction failure. In human imaging studies, both thickness (Milad et al. 2005) and activity (Phelps et al. 2004; Kalisch et al. 2006; Milad et al. 2007b) of ventral mPFC (vmPFC) correlate positively with extinction recall. PTSD patients exhibit decreased activity within vmPFC when exposed to traumatic reminders (Bremner et al. 1999; Shin et al. 2004; Phan et al. 2006), suggesting that the vmPFC in humans is analogous to IL-mPFC in the rodent. In fact, it has recently been shown that PTSD patients are deficient in extinction recall (Milad et al. 2008). Failure to activate these regions supports the hypothesis that PTSD results from extinction failure due to an inability to activate the vmPFC-off switch for fear (Fig. 4). It is also possible that PTSD occurs from an overactive on switch, as the thickness and activity of dorsal anterior cingulate (dACC) cortex, a functional homolog of rat PL-mPFC, correlates with fear expression (Milad et al. 2007a; Fig. 4).

In an analogous manner, drug addicts appear to suffer from an overactive on switch for drug seeking. Cocaine-related cues activate dACC in addicts (Grant et al. 1996; Childress et al. 1999; Garavan et al. 2000), and this activation correlates positively with subjective ratings of cocaine craving (Childress et al. 1999; Fig. 4). Hence, these "drug on" regions may be analogous to PL-mPFC in rodent studies of cocaine relapse. Indeed, these regions are anatomically homologous with rodent PL-mPFC (Ongür and Price 2000; Stefanacci and Amaral 2002). The possibility that these "drug on" regions overlap with "fear on" regions is suggested by

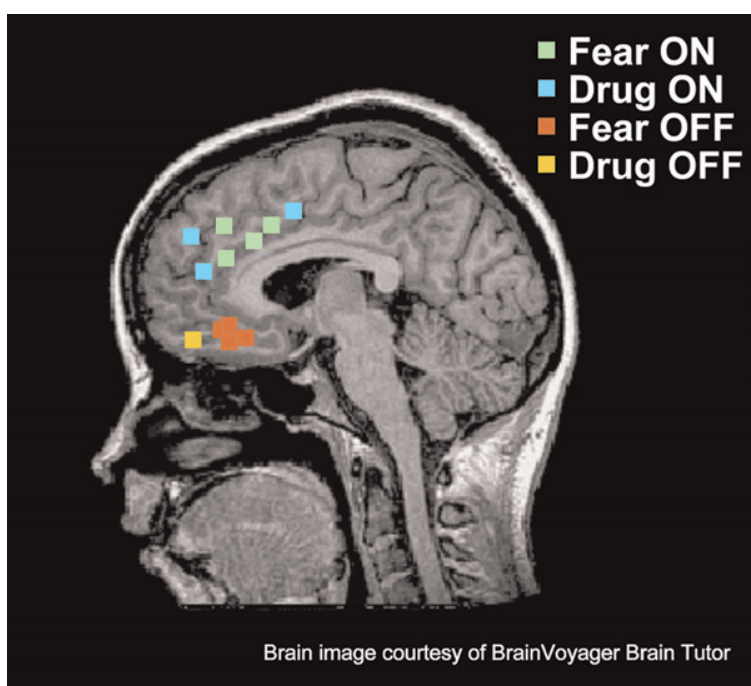

Figure 4. Human homologs of rodent prefrontal areas that modulate fear and addiction. Green dots represent regions of human dACC correlated with fear expression, as assessed by fMRI (Phelps et al. 2004; Milad et al. 2007a). Blue dots represent regions in human addicts correlated with cocaine craving after exposure to cocaine-related cues, as assessed by fMRI (Garavan et al. 2000) or PET mapping of cerebral blood flow using ${ }^{15}$ O-labeled water (Childress et al. 1999). Red dots depict approximate regions of VmPFC that are correlated with fear extinction recall, as assessed by fMRI (Phelps et al. 2004; Kalisch et al. 2006; Milad et al. 2007b). Yellow dot represents the vmPFC equivalent in addicted subjects. This region is deactivated, as assessed by PET metabolic mapping with 2-deoxyglucose, during states of cocaine craving, suggesting a failure to engage extinction (Bonson et al. 2002). Collectively, these studies suggest that this vmPFC is homologous to rodent IL, whereas the dorsal regions of $\mathrm{dACC}$ are homologous to rodent PL. (MRI brain image duplicated with permission from BrainVoyager Brain Tutor software, by Brain Innovation BV, Maastricht, Netherlands.) 
the observation that exposure to trauma-related cues in PTSD patients with comorbid substance dependency triggers cocaine craving (Coffey et al. 2002).

In addition to this cocaine-induced activation of dACC, addicts exhibit widespread decreases in prefrontal metabolism during resting states (Goldstein and Volkow 2002). Studies in monkeys indicate that the ventral-most regions of the prefrontal cortex are the first to show deficits in metabolism after chronic cocaine exposure (Porrino and Lyons 2000; Porrino et al. 2007). Hence, the prefrontal off switch for cocaine seeking may become compromised by cocaine use. Future studies are necessary, however, to determine whether human addicts exhibit deficient prefrontal metabolism even prior to cocaine use, which may render them vulnerable to drug abuse.

Human addicts resemble patients with vmPFC lesions on certain measures of cognitive inhibitory control (Bechara 2005). Both groups are characterized by a type of behavioral impulsivity resulting from an inability to experience negative arousal states normally associated with risky decision making (Bechara et al. 1996; Bechara and Damasio 2002). Interestingly, deactivation of vmPFC has been observed in addicts exposed to cocaine-related cues using positron emission tomography (PET) for glucose metabolism (Bonson et al. 2002). These data suggest that addicts suffer from a deficient off switch in vmPFC, rendering them more susceptible to relapse in the presence of cocaine-related cues. Thus, we suggest that addiction, like anxiety disorders, may result in part from extinction failure.

\section{Comorbidity of anxiety and addiction}

An interaction between circuits for fear and addiction is consistent with behavioral findings. Lifetime cocaine use has been associated with increased feelings of anxiety, a three- to fourfold increase in occurrence of panic attacks, and comorbidity with PTSD (Cox et al. 1990; Wasserman et al. 1997; O'Brien et al. 2005). If subjects are first screened for the presence of an anxiety disorder, the incidence of cocaine use is increased, even after adjusting for sociodemographic traits and other psychotic disorders (Goodwin et al. 2002; Sareen et al. 2006).

A fundamental pathology in prefrontal cortex could conceivably predispose an individual to both anxiety disorders and addiction. Given that vmPFC lesions result in behavioral impulsivity in both humans and rodents (Bechara et al. 1994; Davidson et al. 2000; Best et al. 2002; Chudasama et al. 2003), decreased vmPFC function may result in a high-risk phenotype. In support of this, it has been shown that PTSD patients (Chemtob et al. 1994; Aidman and Kollaras-Mitsinikos 2006; Dileo et al. 2008) and drug addicts (Bechara and Vander 2005; Verdejo-Garcia et al. 2007) are characterized by an impulsive phenotype. However, longitudinal studies with behavioral screening prior to trauma exposure are necessary to determine whether this impulsive phenotype is evident prior to the development of PTSD.

Abnormalities in prefrontal function could arise from stressful life experiences, including trauma, thereby predisposing individuals to develop PTSD and addiction (Anderson et al. 2000; Weber and Reynolds 2004; Hyman et al. 2007). There is epidemiological evidence suggesting a greater incidence of early childhood trauma in PTSD patients (Caffo and Belaise 2003). In rodents, both early life stress and adulthood stress can lead to deficits in fear extinction (Garcia et al. 2008; Matsumoto et al. 2008), possibly due to dendritic retraction in IL-mPFC (Izquierdo et al. 2006). Similarly, stress precipitates relapse in animal models of drug abuse and in humans (Shaham et al. 2000; Sinha et al. 2006).

The effects of stress exposure on prefrontal function could interact with genetic factors to produce a susceptible phenotype. For example, the presence of the dopamine D2 receptor A1 allele has been associated with increased susceptibility to PTSD (Comings et al. 1996) as well as cocaine abuse (Noble et al. 1993; Comings et al. 1994). The presence of this allele results in reduced brain levels of D2 receptors (Noble 2000), which is reminiscent of the deficiencies in striatal dopamine D2 receptor binding observed in human addicts (Volkow et al. 2002). Greater reductions in striatal D2 receptors have furthermore been correlated with greater deficits in resting prefrontal metabolism in addicts (Volkow et al. 1993). Though it must be determined whether these D2 deficits are the cause or the result of addiction, the findings are consistent with a possible genetic determinant for the development of addiction (Noble et al. 1997).

\section{Treating addicts like trauma victims}

Agents that enhance extinction signaling in vmPFC may be effective treatments for disorders that arise from extinction failure. To date, the greatest clinical success has been achieved with D-cycloserine (DCS), a partial agonist of the NMDA receptor, administered in conjunction with exposure therapy for the treatment of anxiety disorders. DCS has been shown to facilitate extinction of acrophobia (Ressler et al. 2004; Davis et al. 2006), social anxiety disorder (Hofmann et al. 2006), and obsessive compulsive disorder (Kushner et al. 2007; Wilhelm et al. 2008). Only recently is DCS being investigated as a possible treatment for addiction (Brady et al. 2008), but studies in rodents support its ability to facilitate extinction of cocaine seeking in a conditioned place preference model of drug reward (Botreau et al. 2006; Paolone et al. 2008). While DCS is thought to act in the amygdala (Ledgerwood et al. 2003), it may also act in the vmPFC, where NMDA-dependent consolidation of extinction takes place (Burgos-Robles et al. 2007; Sotres-Bayon et al. 2008).

By the same token, one might consider treating trauma victims like drug addicts. Recent data suggest that $\mathrm{N}$-acetylcysteine, an over-the-counter cysteine prodrug, may be effective in treating cocaine dependence (LaRowe et al. 2007). This drug is thought to act by restoring glutamate levels in the accumbens of addicts based on data from rodent studies (Baker et al. 2003). Selfadministration of cocaine reduces extracellular glutamate in accumbens by producing an enduring reduction in cystineglutamate exchange, and $\mathrm{N}$-acetylcysteine restores exchanger activity (Baker et al. 2003; Madayag et al. 2007). The restoration of extracellular glutamate by $\mathrm{N}$-acetylcysteine inhibits relapse in animal models by stimulating release-regulating group II metabotropic glutamate receptors (mGluR2/3) (Moran et al. 2005). Importantly, mGluR2/3 agonists reduce both anxiety and the reinstatement of drug seeking in rodents (Schoepp et al. 2003; Baptista et al. 2004; Peters and Kalivas 2006), supporting a glutamatergic link between fear and relapse circuitry. Furthermore, $\mathrm{N}$-acetylcysteine is capable of reducing cravings elicited by cocaine-related cues in humans (LaRowe et al. 2007), as well as cueinduced activity in cingulate cortex (LaRowe et al. 2005). Such a "glutamate restoration" approach could conceivably ameliorate the loss of glutamate resulting from an underactive IL-mPFC, thereby acting to suppress both anxiety and drug seeking.

\section{Testing the model}

Addiction has been recognized as a disorder of learning and memory (Kelley 2004; Hyman 2005). However, few studies have directly compared the neural circuitry controlling an adaptive aversive memory, such as that acquired through Pavlovian fear conditioning, with a maladaptive appetitive memory, such as that acquired in self-administration models of drug abuse. Future studies should be designed to test the validity of the circuitry model we have proposed (Fig. 3) as well as to determine additional 
components of the circuit, be they points of convergence or divergence for fear and addiction.

One approach that would be useful is testing both conditioned fear and conditioned drug-seeking behaviors in the same rat. Burke et al. (2006) used a similar approach to evaluate the effects of chronic cocaine exposure on subsequent extinction of conditioned fear and found that cocaine-exposed rats extinguished more slowly than saline controls. The investigators concluded that cocaine-induced neuroadaptations in prefrontal cortex or its efferent targets impaired the prefrontal-based inhibition of behavior. This is an interesting hypothesis that remains to be investigated. For example, cocaine increases expression of activator of G-protein signaling 3 (AGS3) protein in prefrontal cortex, and reversing this cocaine-induced neuroadaptation reduces cocaine seeking in subsequent relapse tests (Bowers et al. 2004). It would be interesting if reversing this cocaine-induced increase in prefrontal AGS3 expression were sufficient to ameliorate the deficits in fear extinction observed in the Burke et al. (2006) study. Such within-subject testing of both fear and drug seeking should be coupled with lesion techniques, c-fos expression studies, and single-unit recordings to further assess the overlap of extinction circuits.

Recently, the cannabinoid system has received attention for its role in fear extinction (Marsicano et al. 2002; Lin et al. 2008). Agonists for the CB1 cannabinoid receptor, when microinfused into prefrontal cortex, facilitate fear extinction, whereas CB1 antagonists applied locally within prefrontal cortex impair fear extinction (Lin et al. 2008). These effects parallel those of systemic administration of CB1 agents on fear extinction (Marsicano et al. 2002; Chhatwal et al. 2005; Pamplona et al. 2006). While the effects of CB1 agents on the extinction of drug seeking have not been explicitly studied, their effects on the reinstatement of drug seeking contradict the aforementioned findings on fear extinction. That is, CB1 agonists administered systemically induce reinstatement of cocaine and heroin seeking, whereas CB1 antagonists block reinstatement of drug seeking (De Vries et al. 2001, 2003). For heroin seeking, these effects have been localized to the core and IL-mPFC (Alvarez-Jaimes et al. 2008). Hence, these effects of CB1 agents on drug seeking are in apparent opposition to their effects on fear extinction. Future studies are necessary to determine the underlying mechanism behind this discrepancy in the model.

Though we have proposed that extinction results, at least in part, from increased activity within the inhibitory circuit, extinction may also occur via decreased activity within the excitatory circuit. There is evidence that GABAergic inhibitory circuits within PL-mPFC are active on the first cocaine extinction session (Miller and Marshall 2004). This deactivation in PL-mPFC may be necessary to allow activation in IL-mPFC to facilitate extinction learning. The PL-mPFC and IL-mPFC of rodents, and the corresponding homologs in monkeys and humans, are anatomically interconnected regions (Ongür and Price 2000; Chiba et al. 2001; Jones et al. 2005). Future studies are necessary to determine whether reciprocal inhibition occurs between the excitatory and inhibitory output stations of mPFC, or whether PL-mPFC and ILmPFC compete for control of behavior. Pharmacotherapeutics that shift the balance of activity toward activation of the vmPFC combined with deactivation of the dACC would be ideal candidates for the treatment of both anxiety and addiction. Perhaps the two birds of anxiety and addiction can be killed with one prefrontal stone.

\section{Acknowledgments}

Research described in this review was supported by NIH grants MH05383 to J.P., DA012513 and DA005369 to P.W.K, and MH058883 and MH081975 to G.J.Q.

\section{References}

Aidman, E.V. and Kollaras-Mitsinikos, L. 2006. Personality dispositions in the prediction of posttraumatic stress reactions. Psychol. Rep. 99: 569580.

Alvarez-Jaimes, L., Polis, I., and Parsons, L.H. 2008. Attenuation of cueinduced heroin-seeking behavior by cannabinoid CB1 antagonist infusions into the nucleus accumbens core and prefrontal cortex, but not basolateral amygdala. Neuropsychopharmacology 33: 2483-2493.

Anderson, S.W., Damasio, H., Tranel, D., and Damasio, A.R. 2000. Longterm sequelae of prefrontal cortex damage acquired in early childhood. Dev. Neuropsychol. 18: 281-296.

Anglada-Figueroa, D. and Quirk, G.J. 2005. Lesions of the basal amygdala block expression of conditioned fear but not extinction. J. Neurosci. 25: 9680-9685.

Baeg, E.H., Kim, Y.B., Jang, J., Kim, H.T., Mook-Jung, I., and Jung, M.W. 2001. Fast spiking and regular spiking neural correlates of fear conditioning in the medial prefrontal cortex of the rat. Cereb. Cortex 11: $441-451$.

Baker, D.A., McFarland, K., Lake, R.W., Shen, H., Tang, X.C., Toda, S., and Kalivas, P.W. 2003. Neuroadaptations in cystine-glutamate exchange underlie cocaine relapse. Nat. Neurosci. 6: 743-749.

Baptista, M.A., Martin-Fardon, R., and Weiss, F. 2004. Preferential effects of the metabotropic glutamate $2 / 3$ receptor agonist LY379268 on conditioned reinstatement versus primary reinforcement: Comparison between cocaine and a potent conventional reinforcer. J. Neurosci. 24: 4723-4727.

Bechara, A. 2005. Decision making, impulse control and loss of willpower to resist drugs: A neurocognitive perspective. Nat. Neurosci. 8: 1458 1463.

Bechara, A. and Damasio, H. 2002. Decision-making and addiction (part I): Impaired activation of somatic states in substance dependent individuals when pondering decisions with negative future consequences. Neuropsychologia 40: 1675-1689.

Bechara, A. and Vander, L.M. 2005. Decision-making and impulse control after frontal lobe injuries. Curr. Opin. Neurol. 18: 734-739.

Bechara, A., Damasio, A.R., Damasio, H., and Anderson, S.W. 1994. Insensitivity to future consequences following damage to human prefrontal cortex. Cognition 50: 7-15.

Bechara, A., Tranel, D., Damasio, H., and Damasio, A.R. 1996. Failure to respond autonomically to anticipated future outcomes following damage to prefrontal cortex. Cereb. Cortex 6: 215-225.

Berretta, S., Pantazopoulos, H., Caldera, M., Pantazopoulos, P., and Pare, D. 2005. Infralimbic cortex activation increases c-fos expression in intercalated neurons of the amygdala. Neuroscience 132: 943-953.

Best, M., Williams, J.M., and Coccaro, E.F. 2002. Evidence for a dysfunctional prefrontal circuit in patients with an impulsive aggressive disorder. Proc. Natl. Acad. Sci. 99: 8448-8453.

Bissiere, S., Plachta, N., Hoyer, D., McAllister, K.H., Olpe, H.R., Grace, A.A., and Cryan, J.F. 2008. The rostral anterior cingulate cortex modulates the efficiency of amygdala-dependent fear learning. Biol. Psychiatry 63: 821-831.

Blair, H.T., Schafe, G.E., Bauer, E.P., Rodrigues, S.M., and LeDoux, J.E. 2001. Synaptic plasticity in the lateral amygdala: A cellular hypothesis of fear conditioning. Learn. Mem. 8: 229-242.

Blum, S., Hebert, A.E., and Dash, P.K. 2006. A role for the prefrontal cortex in recall of recent and remote memories. Neuroreport 17: 341-344.

Bonson, K.R., Grant, S.J., Contoreggi, C.S., Links, J.M., Metcalfe, J., Weyl, H.L., Kurian, V., Ernst, M., and London, E.D. 2002. Neural systems and cue-induced cocaine craving. Neuropsychopharmacology 26: 376-386.

Botreau, F., Paolone, G., and Stewart, J. 2006. D-Cycloserine facilitates extinction of a cocaine-induced conditioned place preference. Behav. Brain Res. 172: 173-178.

Bowers, M.S., McFarland, K., Lake, R.W., Peterson, Y.K., Lapish, C.C., Gregory, M.L., Lanier, S.M., and Kalivas, P.W. 2004. Activator of G protein signaling 3: A gatekeeper of cocaine sensitization and drug seeking. Neuron 42: 269-281.

Brady, K.T., McRae, A.L., Saladin, M.E., Moran, M.M., and Price, K.L. 2008 D-Cycloserine and cocaine cue extinction. The $70^{\text {th }}$ annual meeting of the college on problems of drug dependence, San Juan, Puerto Rico.

Bremner, J.D., Staib, L.H., Kaloupek, D., Southwick, S.M., Soufer, R., and Charney, D.S. 1999. Neural correlates of exposure to traumatic pictures and sound in Vietnam combat veterans with and without posttraumatic stress disorder: A positron emission tomography study. Biol. Psychiatry 45: $806-816$.

Brinley-Reed, M., Mascagni, F., and McDonald, A.J. 1995. Synaptology of prefrontal cortical projections to the basolateral amygdala: An electron microscopic study in the rat. Neurosci. Lett. 202: 45-48.

Brog, J.S., Salyapongse, A., Deutch, A.Y., and Zahm, D.S. 1993. The patterns of afferent innervation of the core and shell in the "accumbens" part of the rat ventral striatum: Immunohistochemical detection of retrogradely transported fluoro-gold. J. Comp. Neurol. 338: 255-278. 
Burgos-Robles, A., Vidal-Gonzalez, I., Santini, E., and Quirk, G.J. 2007. Consolidation of fear extinction requires NMDA receptor-dependent bursting in the ventromedial prefrontal cortex. Neuron 53: 871-880.

Burgos-Robles, A., Vidal-Gonzalez, I., and Quirk, G.J. 2009. Sustained conditioned responses in prelimbic prefrontal neurons are correlated with fear expression and extinction failure. J. Neurosci. (in press).

Burke, K.A., Franz, T.M., Gugsa, N., and Schoenbaum, G. 2006. Prior cocaine exposure disrupts extinction of fear conditioning. Learn. Mem. 13: 416421.

Caffo, E. and Belaise, C. 2003. Psychological aspects of traumatic injury in children and adolescents. Child Adolesc. Psychiatr. Clin. N.Am. 12: 493-535.

Cammarota, M., Bevilaqua, L.R., Barros, D.M., Vianna, M.R., Izquierdo, L.A., Medina, J.H., and Izquierdo, I. 2005. Retrieval and the extinction of memory. Cell. Mol. Neurobiol. 25: 465-474.

Capriles, N., Rodaros, D., Sorge, R.E., and Stewart, J. 2003. A role for the prefrontal cortex in stress- and cocaine-induced reinstatement of cocaine seeking in rats. Psychopharmacology 168: 66-74.

Chemtob, C.M., Hamada, R.S., Roitblat, H.L., and Muraoka, M.Y. 1994 Anger, impulsivity, and anger control in combat-related posttraumatic stress disorder. J. Consult. Clin. Psychol. 62: 827-832.

Chhatwal, J.P., Davis, M., Maguschak, K.A., and Ressler, K.J. 2005. Enhancing cannabinoid neurotransmission augments the extinction of conditioned fear. Neuropsychopharmacology 30: 516-524.

Chiba, T., Kayahara, T., and Nakano, K. 2001. Efferent projections of infralimbic and prelimbic areas of the medial prefrontal cortex in the Japanese monkey, Macaca fuscata. Brain Res. 888: 83-101.

Childress, A.R., Mozley, P.D., McElgin, W., Fitzgerald, J., Reivich, M., and O'Brien, C.P. 1999. Limbic activation during cue-induced cocaine craving. Am. J. Psychiatry 156: 11-18.

Chudasama, Y., Passetti, F., Rhodes, S.E., Lopian, D., Desai, A., and Robbins, T.W. 2003. Dissociable aspects of performance on the 5-choice serial reaction time task following lesions of the dorsal anterior cingulate, infralimbic and orbitofrontal cortex in the rat: Differential effects on selectivity, impulsivity and compulsivity. Behav. Brain Res. 146: 105119.

Ciccocioppo, R., Sanna, P.P., and Weiss, F. 2001. Cocaine-predictive stimulus induces drug-seeking behavior and neural activation in limbic brain regions after multiple months of abstinence: Reversal by $\mathrm{D}_{1}$ antagonists. Proc. Natl. Acad. Sci. 98: 1976-1981.

Coffey, S.F., Saladin, M.E., Drobes, D.J., Brady, K.T., Dansky, B.S., and Kilpatrick, D.G. 2002. Trauma and substance cue reactivity in individuals with comorbid posttraumatic stress disorder and cocaine or alcohol dependence. Drug Alcohol Depend. 65: 115-127.

Comings, D.E., Muhleman, D., Ahn, C., Gysin, R., and Flanagan, S.D. 1994. The dopamine D2 receptor gene: A genetic risk factor in substance abuse. Drug Alcohol Depend. 34: 175-180.

Comings, D.E., Muhleman, D., and Gysin, R. 1996. Dopamine $\mathrm{D}_{2}$ receptor (DRD2) gene and susceptibility to posttraumatic stress disorder: A study and replication. Biol. Psychiatry 40: 368-372.

Corcoran, K.A. and Quirk, G.J. 2007. Activity in prelimbic cortex is necessary for the expression of learned, but not innate, fears. J. Neurosci. 27: 840-844.

Cornish, J.L. and Kalivas, P.W. 2000. Glutamate transmission in the nucleus accumbens mediates relapse in cocaine addiction. J. Neurosci. 20: RC89.

Cox, B.J., Norton, G.R., Swinson, R.P., and Endler, N.S. 1990. Substance abuse and panic-related anxiety: A critical review. Behav. Res. Ther. 28: 385-393.

Davidson, R.J., Putnam, K.M., and Larson, C.L. 2000. Dysfunction in the neural circuitry of emotion regulation-a possible prelude to violence. Science 289: 591-594.

Davis, M., Ressler, K., Rothbaum, B.O., and Richardson, R. 2006. Effects of D-cycloserine on extinction: Translation from preclinical to clinical work. Biol. Psychiatry 60: 369-375.

Delgado, M.R., Olsson, A., and Phelps, E.A. 2006. Extending animal models of fear conditioning to humans. Biol. Psychol. 73: 39-48.

De Wit, H. and Stewart, J. 1981. Reinstatement of cocaine-reinforced responding in the rat. Psychopharmacology 75: 134-143.

De Vries, T.J., Shaham, Y., Homberg, J.R., Crombag, H., Schuurman, K., Dieben, J., Vanderschuren, L.J., and Schoffelmeer, A.N. 2001. A cannabinoid mechanism in relapse to cocaine seeking. Nat. Med. 7: 1151-1154.

De Vries, T.J., Homberg, J.R., Binnekade, R., Raasø, H., and Schoffelmeer, A.N. 2003. Cannabinoid modulation of the reinforcing and motivational properties of heroin and heroin-associated cues in rats. Psychopharmacology 168: 164-169.

Di Ciano, P. and Everitt, B.J. 2004. Direct interactions between the basolateral amygdala and nucleus accumbens core underlie cocaineseeking behavior by rats. J. Neurosci. 24: 7167-7173.

Di Ciano, P., Benham-Hermetz, J., Fogg, A.P., and Osborne, G.E. 2007. Role of the prelimbic cortex in the acquisition, re-acquisition or persistence of responding for a drug-paired conditioned reinforcer. Neuroscience 150: $291-298$.
Dileo, J.F., Brewer, W.J., Hopwood, M., Anderson, V., and Creamer, M. 2008. Olfactory identification dysfunction, aggression and impulsivity in war veterans with post-traumatic stress disorder. Psychol. Med. 38: 523531.

Di Pietro, N.C., Black, Y.D., and Kantak, K.M. 2006. Context-dependent prefrontal cortex regulation of cocaine self-administration and reinstatement behaviors in rats. Eur. J. Neurosci. 24: 3285-3298.

Epstein, D.H., Preston, K.L., Stewart, J., and Shaham, Y. 2006. Toward a model of drug relapse: An assessment of the validity of the reinstatement procedure. Psychopharmacology 189: 1-16.

Erb, S., Salmaso, N., Rodaros, D., and Stewart, J. 2001. A role for the CRFcontaining pathway from central nucleus of the amygdala to bed nucleus of the stria terminalis in the stress-induced reinstatement of cocaine seeking in rats. Psychopharmacology 158: 360-365.

Fuchs, R.A., Evans, K.A., Ledford, C.C., Parker, M.P., Case, J.M., Mehta, R.H., and See, R.E. 2005. The role of the dorsomedial prefrontal cortex, basolateral amygdala, and dorsal hippocampus in contextual reinstatement of cocaine seeking in rats. Neuropsychopharmacology 30: 296-309.

Fuchs, R.A., Eaddy, J.L., Su, Z.I., and Bell, G.H. 2007. Interactions of the basolateral amygdala with the dorsal hippocampus and dorsomedial prefrontal cortex regulate drug context-induced reinstatement of cocaine-seeking in rats. Eur. J. Neurosci. 26: 487-498.

Fuster, J.M. 2002. Frontal lobe and cognitive development. J. Neurocytol. 31: 373-385.

Gabbott, P.L., Warner, T.A., Jays, P.R., Salway, P., and Busby, S.J. 2005 Prefrontal cortex in the rat: Projections to subcortical autonomic, motor, and limbic centers. J. Comp. Neurol. 492: 145-177.

Garavan, H. and Hester, R. 2007. The role of cognitive control in cocaine dependence. Neuropsychol. Rev. 17: 337-345.

Garavan, H., Pankiewicz, J., Bloom, A., Cho, J.K., Sperry, L., Ross, T.J., Salmeron, B.J., Risinger, R., Kelley, D., and Stein, E.A. 2000. Cue-induced cocaine craving: Neuroanatomical specificity for drug users and drug stimuli. Am. J. Psychiatry 157: 1789-1798.

Garcia, R., Spennato, G., Nilsson-Todd, L., Moreau, J.L., and Deschaux, O. 2008. Hippocampal low-frequency stimulation and chronic mild stress similarly disrupt fear extinction memory in rats. Neurobiol. Learn. Mem. 89: $560-566$.

Gilmartin, M.R. and McEchron, M.D. 2005. Single neurons in the medial prefrontal cortex of the rat exhibit tonic and phasic coding during trace fear conditioning. Behav. Neurosci. 119: 1496-1510.

Goldstein, R.Z. and Volkow, N.D. 2002. Drug addiction and its underlying neurobiological basis: Neuroimaging evidence for the involvement of the frontal cortex. Am. J. Psychiatry 159: 1642-1652.

Gonzalez-Lima, F. and Bruchey, A.K. 2004. Extinction memory improvement by the metabolic enhancer methylene blue. Learn. Mem. 11: $633-640$

Goodwin, R.D., Stayner, D.A., Chinman, M.J., Wu, P., Tebes, J.K., and Davidson, L. 2002. The relationship between anxiety and substance use disorders among individuals with severe affective disorders. Compr. Psychiatry 43: 245-252.

Grant, S., London, E.D., Newlin, D.B., Villemagne, V.L., Liu, X., Contoreggi, C., Phillips, R.L., Kimes, A.S., and Margolin, A. 1996. Activation of memory circuits during cue-elicited cocaine craving. Proc. Natl. Acad. Sci. 93: 12040-12045.

Haralambous, T. and Westbrook, R.F. 1999. An infusion of bupivacaine into the nucleus accumbens disrupts the acquisition but not the expression of contextual fear conditioning. Behav. Neurosci. 113: 925-940.

Heimer, L., Zahm, D.S., Churchill, L., Kalivas, P.W., and Wohltmann, C. 1991. Specificity in the projection patterns of accumbal core and shell in the rat. Neuroscience 41: 89-125.

Herry, C. and Garcia, R. 2002. Prefrontal cortex long-term potentiation, but not long-term depression, is associated with the maintenance of extinction of learned fear in mice. J. Neurosci. 22: 577-583.

Herry, C., Ciocchi, S., Senn, V., Demmou, L., Muller, C., and Luthi, A. 2008. Switching on and off fear by distinct neuronal circuits. Nature 454: 600606.

Hikind, N. and Maroun, M. 2008. Microinfusion of the D1 receptor antagonist, SCH23390 into the IL but not the BLA impairs consolidation of extinction of auditory fear conditioning. Neurobiol. Learn. Mem. 90: 217-222.

Hofmann, S.G., Meuret, A.E., Smits, J.A., Simon, N.M., Pollack, M.H., Eisenmenger, K., Shiekh, M., and Otto, M.W. 2006. Augmentation of exposure therapy with D-cycloserine for social anxiety disorder. Arch. Gen. Psychiatry 63: 298-304.

Hooks, M.S. and Kalivas, P.W. 1995. The role of mesoaccumbens-pallidal circuitry in novelty-induced behavioral activation. Neuroscience 64: 587-597.

Hopkins, D.A. and Holstege, G. 1978. Amygdaloid projections to the mesencephalon, pons and medulla oblongata in the cat. Exp. Brain Res. 32: 529-547.

Hugues, S., Deschaux, O., and Garcia, R. 2004. Postextinction infusion of a mitogen-activated protein kinase inhibitor into the medial prefrontal 
cortex impairs memory of the extinction of conditioned fear. Learn. Mem. 11: 540-543.

Hyman, S.E. 2005. Addiction: A disease of learning and memory. Am. J. Psychiatry 162: 1414-1422.

Hyman, S.M., Paliwal, P., and Sinha, R. 2007. Childhood maltreatment, perceived stress, and stress-related coping in recently abstinent cocaine dependent adults. Psychol. Addict. Behav. 21: 233-238.

Izquierdo, A., Wellman, C.L., and Holmes, A. 2006. Brief uncontrollable stress causes dendritic retraction in infralimbic cortex and resistance to fear extinction in mice. J. Neurosci. 26: $5733-5738$.

Jones, B.F., Groenewegen, H.J., and Witter, M.P. 2005. Intrinsic connections of the cingulate cortex in the rat suggest the existence of multiple functionally segregated networks. Neuroscience 133: 193-207.

Jongen-Relo, A.L., Kaufmann, S., and Feldon, J. 2003. A differential involvement of the shell and core subterritories of the nucleus accumbens of rats in memory processes. Behav. Neurosci. 117: 150168.

Jüngling, K., Seidenbecher, T., Sosulina, L., Lesting, J., Sangha, S., Clark, S.D., Okamura, N., Duangdao, D.M., Xu, Y.L., Reinscheid, R.K., et al. 2008. Neuropeptide S-mediated control of fear expression and extinction: Role of intercalated GABAergic neurons in the amygdala. Neuron 59: 298-310.

Kalisch, R., Korenfeld, E., Stephan, K.E., Weiskopf, N., Seymour, B., and Dolan, R.J. 2006. Context-dependent human extinction memory is mediated by a ventromedial prefrontal and hippocampal network. $J$. Neurosci. 26: 9503-9511.

Kalivas, P.W., Churchill, L., and Romanides, A. 1999. Involvement of the pallidal-thalamocortical circuit in adaptive behavior. Ann. N. Y. Acad. Sci. 877: 64-70.

Kalivas, P.W., Jackson, D., Romanidies, A., Wyndham, L., and Duffy, P. 2001. Involvement of pallidothalamic circuitry in working memory. Neuroscience 104: 129-136.

Kalivas, P.W., Volkow, N., and Seamans, J. 2005. Unmanageable motivation in addiction: A pathology in prefrontal-accumbens glutamate transmission. Neuron 45: 647-650.

Kantak, K.M., Black, Y., Valencia, E., Green-Jordan, K., and Eichenbaum, H.B. 2002. Dissociable effects of lidocaine inactivation of the rostral and caudal basolateral amygdala on the maintenance and reinstatement of cocaine-seeking behavior in rats. J. Neurosci. 22: 1126-1136.

Kelley, A.E. 2004. Memory and addiction: Shared neural circuitry and molecular mechanisms. Neuron 44: 161-179.

Kim, J., Lee, S., Park, K., Hong, I., Song, B., Son, G., Park, H., Kim, W.R., Park, E., Choe, H.K., et al. 2007. Amygdala depotentiation and fear extinction. Proc. Natl. Acad. Sci. 104: 20955-20960.

Komiskey, H.L., Miller, D.D., LaPidus, J.B., and Patil, P.N. 1977. The isomers of cocaine and tropacocaine: Effect on $3 \mathrm{H}$-catecholamine uptake by rat brain synaptosomes. Life Sci. 21: 1117-1122.

Konorski, J. 1967. Integrative Activity of the Brain. University of Chicago Press, Chicago, IL.

Koya, E., Uejima, J.L., Wihbey, K.A., Bossert, J.M., Hope, B.T., and Shaham, Y. 2008. Role of ventral medial prefrontal cortex in incubation of cocaine craving. Neuropharmacology 56: 177-185.

Kushner, M.G., Kim, S.W., Donahue, C., Thuras, P., Adson, D., Kotlyar, M., McCabe, J., Peterson, J., and Foa, E.B. 2007. D-cycloserine augmented exposure therapy for obsessive-compulsive disorder. Biol. Psychiatry 62 835-838.

LaLumiere, R.T. and Kalivas, P.W. 2008. Glutamate release in the nucleus accumbens core is necessary for heroin seeking. J. Neurosci. 28: 31703177.

LaRowe, S.D., Myrick, H., Malcolm, R., and Kalivas, P. 2005. Cue reactivity and neuroimaging in cocaine-dependent subjects: A double-blind placebo-controlled pilot study involving $\mathrm{N}$-acetylcysteine. In Proceedings of the 35th annual meeting of the Society for Neuroscience. Washington, DC

LaRowe, S.D., Myrick, H., Hedden, S., Mardikian, P., Saladin, M., McRae, A., Brady, K., Kalivas, P.W., and Malcolm, R. 2007. Is cocaine desire reduced by $\mathrm{N}$-acetylcysteine? Am. J. Psychiatry 164: 1115-1117.

Laviolette, S.R., Lipski, W.J., and Grace, A.A. 2005. A subpopulation of neurons in the medial prefrontal cortex encodes emotional learning with burst and frequency codes through a dopamine D4 receptordependent basolateral amygdala input. J. Neurosci. 25: 6066-6075.

Ledgerwood, L., Richardson, R., and Cranney, J. 2003. Effects of D-cycloserine on extinction of conditioned freezing. Behav. Neurosci. 117: $341-349$.

LeDoux, J.E., Iwata, J., Cicchetti, P., and Reis, D.J. 1988. Different projections of the central amygdaloid nucleus mediate autonomic and behavioral correlates of conditioned fear. J. Neurosci. 8: 25172529.

Leri, F., Flores, J., Rodaros, D., and Stewart, J. 2002. Blockade of stressinduced but not cocaine-induced reinstatement by infusion of noradrenergic antagonists into the bed nucleus of the stria terminalis or the central nucleus of the amygdala. J. Neurosci. 22: 5713-5718.
Levita, L., Dalley, J.W., and Robbins, T.W. 2002. Nucleus accumbens dopamine and learned fear revisited: A review and some new findings. Behav. Brain Res. 137: 115-127.

Li, G., Nair, S.S., and Quirk, G.J. 2009. A biologically realistic network model of acquisition and extinction of conditioned fear associations in lateral amygdala neurons. J. Neurophysiol. 101: 1629-1646.

Likhtik, E., Pelletier, J.G., Paz, R., and Pare, D. 2005. Prefrontal control of the amygdala. J. Neurosci. 25: 7429-7437.

Likhtik, E., Popa, D., Apergis-Schoute, J., Fidacaro, G.A., and Pare, D. 2008. Amygdala intercalated neurons are required for expression of fear extinction. Nature 454: 642-645.

Lin, H.C., Mao, S.C., Su, C.L., and Gean, P.W. 2008. The role of prefrontal cortex CB1 receptors in the modulation of fear memory. Cereb. Cortex 19: $165-176$

Madayag, A., Lobner, D., Kau, K.S., Mantsch, J.R., Abdulhameed, O., Hearing, M., Grier, M.D., and Baker, D.A. 2007. Repeated $N$-acetylcysteine administration alters plasticity-dependent effects of cocaine. J. Neurosci. 27: 1396813976

Maren, S. 2005. Building and burying fear memories in the brain. Neuroscientist 11: 89-99.

Marsicano, G., Wotjak, C.T., Azad, S.C., Bisogno, T., Rammes, G., Cascio, M.G., Hermann, H., Tang, J., Hofmann, C., Zieglgänsberger, W., et al. 2002. The endogenous cannabinoid system controls extinction of aversive memories. Nature 418: 530-534.

Matsumoto, M., Togashi, H., Konno, K., Koseki, H., Hirata, R., Izumi, T. Yamaguchi, T., and Yoshioka, M. 2008. Early postnatal stress alters the extinction of context-dependent conditioned fear in adult rats. Pharmacol. Biochem. Behav. 89: 247-252.

McDonald, A.J., Mascagni, F., and Guo, L. 1996. Projections of the medial and lateral prefrontal cortices to the amygdala: A Phaseolus vulgaris leucoagglutinin study in the rat. Neuroscience 71: 55-75.

McFarland, K. and Kalivas, P.W. 2001. The circuitry mediating cocaineinduced reinstatement of drug-seeking behavior. J. Neurosci. 21: 86558663.

McFarland, K., Lapish, C.C., and Kalivas, P.W. 2003. Prefrontal glutamate release into the core of the nucleus accumbens mediates cocaineinduced reinstatement of drug-seeking behavior. J. Neurosci. 23: 35313537.

McFarland, K., Davidge, S.B., Lapish, C.C., and Kalivas, P.W. 2004. Limbic and motor circuitry underlying foot shock-induced reinstatement of cocaine-seeking behavior. J. Neurosci. 24: 1551-1560.

McLaughlin, J. and See, R.E. 2003. Selective inactivation of the dorsomedial prefrontal cortex and the basolateral amygdala attenuates conditionedcued reinstatement of extinguished cocaine-seeking behavior in rats. Psychopharmacology 168: 57-65.

McLaughlin, R.J. and Floresco, S.B. 2007. The role of different subregions of the basolateral amygdala in cue-induced reinstatement and extinction of food-seeking behavior. Neuroscience 146: 1484-1494.

Milad, M.R. and Quirk, G.J. 2002. Neurons in medial prefrontal cortex signal memory for fear extinction. Nature 420: 70-74

Milad, M.R., Vidal-Gonzalez, I., and Quirk, G.J. 2004. Electrical stimulation of medial prefrontal cortex reduces conditioned fear in a temporally specific manner. Behav. Neurosci. 118: 389-394.

Milad, M.R., Quinn, B.T., Pitman, R.K., Orr, S.P., Fischl, B., and Rauch, S.L. 2005. Thickness of ventromedial prefrontal cortex in humans is correlated with extinction memory. Proc. Natl. Acad. Sci. 102: 1070610711.

Milad, M.R., Rauch, S.L., Pitman, R.K., and Quirk, G.J. 2006. Fear extinction in rats: Implications for human brain imaging and anxiety disorders. Biol. Psychol. 73: 61-71.

Milad, M.R., Quirk, G.J., Pitman, R.K., Orr, S.P., Fischl, B., and Rauch, S.L. $2007 \mathrm{a}$. A role of the human dorsal anterior cingulate cortex in expression of learned fear. Biol. Psychiatry 62: 1191-1194.

Milad, M.R., Wright, C.I., Orr, S.P., Pitman, R.K., Quirk, G.J., and Rauch, S.L $2007 \mathrm{~b}$. Recall of fear extinction in humans activates the ventromedial prefrontal cortex and hippocampus in concert. Biol. Psychiatry 62: 446454.

Milad, M.R., Orr, S.P., Lasko, N.B., Chang, Y., Rauch, S.L., and Pitman, R.K. 2008. Presence and acquired origin of reduced recall for fear extinction in PTSD: Results of a twin study. J. Psychiatr. Res. 42: 515-520.

Miller, E.K. 2000. The prefrontal cortex and cognitive control. Nat. Rev. Neurosci. 1: 59-65.

Miller, C.A. and Marshall, J.F. 2004. Altered prelimbic cortex output during cue-elicited drug seeking. J. Neurosci. 24: 6889-6897.

Mogenson, G.J. and Nielsen, M.A. 1983. Evidence that an accumbens to subpallidal GABAergic projection contributes to locomotor activity. Brain Res. Bull. 11: 309-314.

Moran, M.M., McFarland, K., Melendez, R.I., Kalivas, P.W., and Seamans, J.K. 2005. Cystine/glutamate exchange regulates metabotropic glutamate receptor presynaptic inhibition of excitatory transmission and vulnerability to cocaine seeking. J. Neurosci. 25: 63896393. 
Morgan, M.A. and LeDoux, J.E. 1995. Differential contribution of dorsal and ventral medial prefrontal cortex to the acquisition and extinction of conditioned fear in rats. Behav. Neurosci. 109: 681-688.

Morgan, M.A., Romanski, L.M., and LeDoux, J.E. 1993. Extinction of emotional learning: Contribution of medial prefrontal cortex. Neurosci. Lett. 163: 109-113.

Mueller, D., Porter, J.T., and Quirk, G.J. 2008. Noradrenergic signaling in infralimbic cortex increases cell excitability and strengthens memory for fear extinction. J. Neurosci. 28: 369-375.

Myers, K.M. and Davis, M. 2007. Mechanisms of fear extinction. Mol. Psychiatry 12: 120-150.

Noble, E.P. 2000. Addiction and its reward process through polymorphisms of the $\mathrm{D}_{2}$ dopamine receptor gene: A review. Eur. Psychiatry 15: 79-89.

Noble, E.P., Blum, K., Khalsa, M.E., Ritchie, T., Montgomery, A., Wood, R.C., Fitch, R.J., Ozkaragoz, T., Sheridan, P.J., and Anglin, M.D. 1993. Allelic association of the $\mathrm{D}_{2}$ dopamine receptor gene with cocaine dependence. Drug Alcohol Depend. 33: 271-285.

Noble, E.P., Gottschalk, L.A., Fallon, J.H., Ritchie, T.L., and Wu, J.C. 1997. $\mathrm{D}_{2}$ dopamine receptor polymorphism and brain regional glucose metabolism. Am. J. Med. Genet. 74: 162-166.

O'Brien, M.S., Wu, L.T., and Anthony, J.C. 2005. Cocaine use and the occurrence of panic attacks in the community: A case-crossover approach. Subst. Use Misuse 40: 285-297.

Ongür, D. and Price, J.L. 2000. The organization of networks within the orbital and medial prefrontal cortex of rats, monkeys and humans. Cereb. Cortex 10: 206-219.

Ovari, J. and Leri, F. 2008. Inactivation of the ventromedial prefrontal cortex mimics re-emergence of heroin seeking caused by heroin reconditioning. Neurosci. Lett. 444: 52-55.

Pamplona, F.A., Prediger, R.D., Pandolfo, P., and Takahashi, R.N. 2006. The cannabinoid receptor agonist WIN 55,212-2 facilitates the extinction of contextual fear memory and spatial memory in rats. Psychopharmacology 188: 641-649.

Paolone, G., Botreau, F., and Stewart, J. 2008. The facilitative effects of Dcycloserine on extinction of a cocaine-induced conditioned place preference can be long lasting and resistant to reinstatement. Psychopharmacology (Berl) 202: 403-409.

Park, W.K., Bari, A.A., Jey, A.R., Anderson, S.M., Spealman, R.D., Rowlett, J.K., and Pierce, R.C. 2002. Cocaine administered into the medial prefrontal cortex reinstates cocaine-seeking behavior by increasing AMPA receptor-mediated glutamate transmission in the nucleus accumbens. J. Neurosci. 22: 2916-2925.

Paxinos, G. and Watson, C. 2005. The rat brain in stereotaxic coordinates, 5 th ed. Academic Press, New York.

Peters, J. and Kalivas, P.W. 2006. The group II metabotropic glutamate receptor agonist, LY379268, inhibits both cocaine- and food-seeking behavior in rats. Psychopharmacology 186: 143-149.

Peters, J., LaLumiere, R.T., and Kalivas, P.W. 2008a. Infralimbic prefrontal cortex is responsible for inhibiting cocaine seeking in extinguished rats. J. Neurosci. 28: 6046-6053.

Peters, J., Vallone, J., Laurendi, K., and Kalivas, P.W. 2008b. Opposing roles for the ventral prefrontal cortex and the basolateral amygdala on the spontaneous recovery of cocaine-seeking in rats. Psychopharmacology 197: 319-326.

Phan, K.L., Britton, J.C., Taylor, S.F., Fig, L.M., and Liberzon, I. 2006. Corticolimbic blood flow during nontraumatic emotional processing in posttraumatic stress disorder. Arch. Gen. Psychiatry 63: 184-192.

Phelps, E.A., Delgado, M.R., Nearing, K.I., and LeDoux, J.E. 2004. Extinction learning in humans: Role of the amygdala and vmPFC. Neuron 43: 897905.

Porrino, L.J. and Lyons, D. 2000. Orbital and medial prefrontal cortex and psychostimulant abuse: Studies in animal models. Cereb. Cortex 10: 326-333.

Porrino, L.J., Smith, H.R., Nader, M.A., and Beveridge, T.J. 2007. The effects of cocaine: A shifting target over the course of addiction. Prog. Neuropsychopharmacol. Biol. Psychiatry 31: 1593-1600.

Powell, D.A., Skaggs, H., Churchwell, J., and McLaughlin, J. 2001. Posttraining lesions of the medial prefrontal cortex impair performance of Pavlovian eyeblink conditioning but have no effect on concomitant heart rate changes in rabbits (Oryctolagus cuniculus). Behav. Neurosci. 115: $1029-1038$.

Quirk, G.J. and Beer, J.S. 2006. Prefrontal involvement in the regulation of emotion: Convergence of rat and human studies. Curr. Opin. Neurobiol. 16: $723-727$.

Quirk, G.J. and Mueller, D. 2008. Neural mechanisms of extinction learning and retrieval. Neuropsychopharmacology 33: 56-72.

Quirk, G.J., Repa, C., and LeDoux, J.E. 1995. Fear conditioning enhances short-latency auditory responses of lateral amygdala neurons: Parallel recordings in the freely behaving rat. Neuron 15: 1029-1039.

Repa, J.C., Muller, J., Apergis, J., Desrochers, T.M., Zhou, Y., and LeDoux, J.E. 2001. Two different lateral amygdala cell populations contribute to the initiation and storage of memory. Nat. Neurosci. 4: 724-731.
Rescorla, R.A. 2004. Spontaneous recovery. Learn. Mem. 11: 501-509. Ressler, K.J., Rothbaum, B.O., Tannenbaum, L., Anderson, P., Graap, K., Zimand, E., Hodges, L., and Davis, M. 2004. Cognitive enhancers as adjuncts to psychotherapy: Use of D-cycloserine in phobic individuals to facilitate extinction of fear. Arch. Gen. Psychiatry 61: 1136-1144.

Reynolds, S.M. and Berridge, K.C. 2001. Fear and feeding in the nucleus accumbens shell: Rostrocaudal segregation of GABA-elicited defensive behavior versus eating behavior. J. Neurosci. 21: 3261-3270.

Reynolds, S.M. and Berridge, K.C. 2002. Positive and negative motivation in nucleus accumbens shell: Bivalent rostrocaudal gradients for GABAelicited eating, taste "liking"/"disliking" reactions, place preference/ avoidance, and fear. J. Neurosci. 22: 7308-7320.

Rogers, J.L., Ghee, S., and See, R.E. 2008. The neural circuitry underlying reinstatement of heroin-seeking behavior in an animal model of relapse. Neuroscience 151: 579-588.

Royer, S. and Pare, D. 2002. Bidirectional synaptic plasticity in intercalated amygdala neurons and the extinction of conditioned fear responses. Neuroscience 115: 455-462.

Sanchez, C.J., Bailie, T.M., Wu, W.R., Li, N., and Sorg, B.A. 2003. Manipulation of dopamine D1-like receptor activation in the rat medial prefrontal cortex alters stress- and cocaine-induced reinstatement of conditioned place preference behavior. Neuroscience 119: 497-505.

Santini, E., Ge, H., Ren, K., Pena, D.O., and Quirk, G.J. 2004. Consolidation of fear extinction requires protein synthesis in the medial prefrontal cortex. J. Neurosci. 24: 5704-5710.

Sareen, J., Chartier, M., Paulus, M.P., and Stein, M.B. 2006. Illicit drug use and anxiety disorders: Findings from two community surveys. Psychiatry Res. 142: 11-17.

Schmidt, E.D., Voorn, P., Binnekade, R., Schoffelmeer, A.N., and De Vries, T.J. 2005. Differential involvement of the prelimbic cortex and striatum in conditioned heroin and sucrose seeking following long-term extinction. Eur. J. Neurosci. 22: 2347-2356.

Schoepp, D.D., Wright, R.A., Levine, L.R., Gaydos, B., and Potter, W.Z. 2003. LY354740, an mGlu2/3 receptor agonist as a novel approach to treat anxiety/stress. Stress 6: 189-197.

Schroeder, J.A. and Schneider, J.S. 2002. GABA-opioid interactions in the globus pallidus: [D-Ala2]-Met-enkephalinamide attenuates potassiumevoked GABA release after nigrostriatal lesion. J. Neurochem. 82: 666673.

Schwienbacher, I., Fendt, M., Richardson, R., and Schnitzler, H.U. 2004. Temporary inactivation of the nucleus accumbens disrupts acquisition and expression of fear-potentiated startle in rats. Brain Res. 1027: 87-93.

See, R.E. 2005. Neural substrates of cocaine-cue associations that trigger relapse. Eur. J. Pharmacol. 526: 140-146.

Sesack, S.R., Deutch, A.Y., Roth, R.H., and Bunney, B.S. 1989. Topographical organization of the efferent projections of the medial prefrontal cortex in the rat: An anterograde tract-tracing study with Phaseolus vulgaris leucoagglutinin. J. Comp. Neurol. 290: 213-242.

Shaham, Y., Erb, S., and Stewart, J. 2000. Stress-induced relapse to heroin and cocaine seeking in rats: A review. Brain Res. Brain Res. Rev. 33: 13-33.

Shaham, Y., Shalev, U., Lu, L., De Wit, H., and Stewart, J. 2003. The reinstatement model of drug relapse: History, methodology and major findings. Psychopharmacology 3-20.

Shin, L.M., Orr, S.P., Carson, M.A., Rauch, S.L., Macklin, M.L., Lasko, N.B., Peters, P.M., Metzger, L.J., Dougherty, D.D., Cannistraro, P.A., et al. 2004. Regional cerebral blood flow in the amygdala and medial prefrontal cortex during traumatic imagery in male and female Vietnam veterans with PTSD. Arch. Gen. Psychiatry 61: 168-176.

Sierra-Mercado, D., Corcoran, K.A., Lebron-Milad, K., and Quirk, G.J. 2006. Inactivation of ventromedial prefrontal cortex reduces expression of conditioned fear and impairs subsequent recall of extinction. Eur. J. Neurosci. 24: $1751-1758$.

Sinha, R., Garcia, M., Paliwal, P., Kreek, M.J., and Rounsaville, B.J. 2006. Stress-induced cocaine craving and hypothalamic-pituitary-adrenal responses are predictive of cocaine relapse outcomes. Arch. Gen. Psychiatry 63: 324-331.

Sotres-Bayon, F., Cain, C.K., and LeDoux, J.E. 2006. Brain mechanisms of fear extinction: Historical perspectives on the contribution of prefrontal cortex. Biol. Psychiatry 60: 329-336.

Sotres-Bayon, F., Diaz-Mataix, L., Bush, D.E., and LeDoux, J.E. 2008. Dissociable roles for the ventromedial prefrontal cortex and amygdala in fear extinction: NR2B contribution. Cereb. Cortex 19: 474-482.

Stefanacci, L. and Amaral, D.G. 2002. Some observations on cortical inputs to the macaque monkey amygdala: An anterograde tracing study. $J$. Comp. Neurol. 451: 301-323.

Sun, W. and Rebec, G.V. 2005. The role of prefrontal cortex D1-like and D2like receptors in cocaine-seeking behavior in rats. Psychopharmacology 177: 315-323.

Sutton, M.A., Schmidt, E.F., Choi, K.H., Schad, C.A., Whisler, K., Simmons, D., Karanian, D.A., Monteggia, L.M., Neve, R.L., and Self, D.W. 2003. Extinction-induced upregulation in AMPA receptors reduces cocaineseeking behaviour. Nature 421: 70-75. 
Tang, X.C., McFarland, K., Cagle, S., and Kalivas, P.W. 2005. Cocaineinduced reinstatement requires endogenous stimulation of $\mu$-opioid receptors in the ventral pallidum. J. Neurosci. 25: 4512-4520.

Torregrossa, M.M., Tang, X.C., and Kalivas, P.W. 2008. The glutamatergic projection from the prefrontal cortex to the nucleus accumbens core is required for cocaine-induced decreases in ventral pallidal GABA. Neurosci. Lett. 438: 142-145.

Verdejo-Garcia, A., Bechara, A., Recknor, E.C., and Perez-Garcia, M. 2007. Negative emotion-driven impulsivity predicts substance dependence problems. Drug Alcohol Depend. 91: 213-219.

Vertes, R.P. 2004. Differential projections of the infralimbic and prelimbic cortex in the rat. Synapse 51: 32-58.

Vidal-Gonzalez, I., Vidal-Gonzalez, B., Rauch, S.L., and Quirk, G.J. 2006. Microstimulation reveals opposing influences of prelimbic and infralimbic cortex on the expression of conditioned fear. Learn. Mem. 13: $728-733$.

Volkow, N.D., Fowler, J.S., Wang, G.J., Hitzemann, R., Logan, J., Schlyer, D.J., Dewey, S.L., and Wolf, A.P. 1993. Decreased dopamine D2 receptor availability is associated with reduced frontal metabolism in cocaine abusers. Synapse 14: 169-177.

Volkow, N.D., Fowler, J.S., and Wang, G.J. 2002. Role of dopamine in drug reinforcement and addiction in humans: Results from imaging studies. Behav. Pharmacol. 13: 355-366.

Voorn, P., Vanderschuren, L.J., Groenewegen, H.J., Robbins, T.W., and Pennartz, C.M. 2004. Putting a spin on the dorsal-ventral divide of the striatum. Trends Neurosci. 27: 468-474.

Walaas, I. and Fonnum, F. 1979. The distribution and origin of glutamate decarboxylase and choline acetyltransferase in ventral pallidum and other basal forebrain regions. Brain Res. 177: 325-336.
Waldhoer, M., Bartlett, S.E., and Whistler, J.L. 2004. Opioid receptors. Annu. Rev. Biochem. 73: 953-990.

Wasserman, D.A., Havassy, B.E., and Boles, S.M. 1997. Traumatic events and post-traumatic stress disorder in cocaine users entering private treatment. Drug Alcohol Depend. 46: 1-8.

Weber, D.A. and Reynolds, C.R. 2004. Clinical perspectives on neurobiological effects of psychological trauma. Neuropsychol. Rev. 14: $115-129$.

Wilensky, A.E., Schafe, G.E., Kristensen, M.P., and LeDoux, J.E. 2006. Rethinking the fear circuit: The central nucleus of the amygdala is required for the acquisition, consolidation, and expression of Pavlovian fear conditioning. J. Neurosci. 26: 12387-12396.

Wilhelm, S., Buhlmann, U., Tolin, D.F., Meunier, S.A., Pearlson, G.D., Reese, H.E., Cannistraro, P., Jenike, M.A., and Rauch, S.L. 2008. Augmentation of behavior therapy with D-cycloserine for obsessive-compulsive disorder. Am. J. Psychiatry 165: 335-341.

Zahm, D.S. and Heimer, L. 1990. Two transpallidal pathways originating in the rat nucleus accumbens. J. Comp. Neurol. 302: 437-446.

Zahm, D.S., Zaborszky, L., Alones, V.E., and Heimer, L. 1985. Evidence for the coexistence of glutamate decarboxylase and Met-enkephalin immunoreactivities in axon terminals of rat ventral pallidum. Brain Res. 325: $317-321$.

Zimmerman, J.M., Rabinak, C.A., McLachlan, I.G., and Maren, S. 2007. The central nucleus of the amygdala is essential for acquiring and expressing conditional fear after overtraining. Learn. Mem. 14: 634644 .

Received September 30, 2008; accepted in revised form January 20, 2009. 


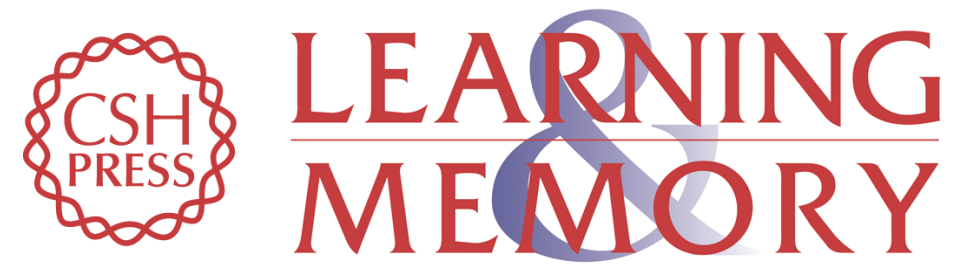

\section{Extinction circuits for fear and addiction overlap in prefrontal cortex}

Jamie Peters, Peter W. Kalivas and Gregory J. Quirk

Learn. Mem. 2009, 16:

Access the most recent version at doi:10.1101//m.1041309

References This article cites 187 articles, 41 of which can be accessed free at:

http://learnmem.cshlp.org/content/16/5/279.full.html\#ref-list-1

License

Email Alerting Receive free email alerts when new articles cite this article - sign up in the box at the Service top right corner of the article or click here. 